\title{
LUC:RÉCIIA E O IDEAL ROMANO DE MULHER
}

\author{
Ariovaldo A. Pelcrlini
}

RISSUMO: Muila coisa se explica pelo atual, mas é bem mais ampla a herança yue hai mister do passado como seu legílimo e profundo intérprete. $O$ ickal romano antigo cke mulher, que pxule ser reconstituích à lız dos texlus, yuer dirctamente dus yuadrus pusitivos, yuer e.r opposito das visūes negalivas, $\dot{\mathrm{e}}$, sem duividii, IIII dos subsíclios de que poxte valer-se o estuctu da siluaçĩo da mulher no pensamenlo e na socicchede de nossa épuca. A conlecer esse icleal nos ajudarão a crílica caluniana das reivincličç̧óes femininas em prol da abrogaçĩo da lei Ópia; a mençîo da igualdacke de direitus ch espuxa e ku maricho como uma chs

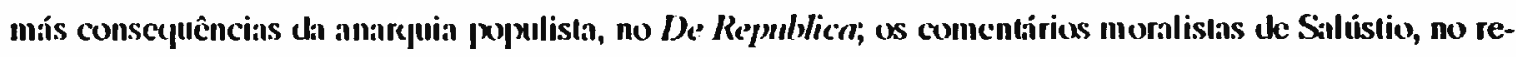
Iralo de Semprônia; a revoluçĩo clus neóteroi, ao pro|xorem a existência ck uma élica cku sentimento, danch à mulher 0 dircito de amar, de escolher, de consenlir a sua telicidack; o comedimento horaciano cntre o amor-paixão c o "digno" da mulher de "Lamilia"; enfim, o lexto imorlal da violaçî́o e morte de Lucrécin,

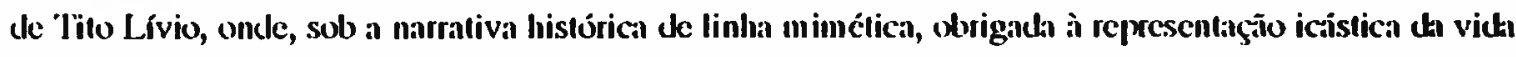
humani, conı a Iensî̃o c concentração dramílica da re|resentaçño trígica, entrevemos ubjetivus diukscáli-

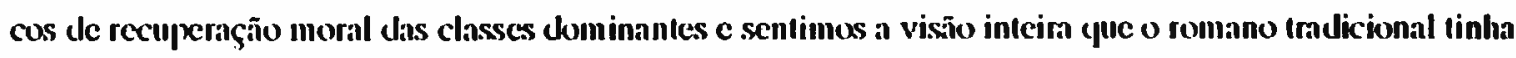
da mulher, amarrada por preconceilus que violentavam uma moral racional, cm nome até ch "ciência" ha epxea. İ uma mulher inteligente e "romana" como Lucrécia conhecia seu inico caminho... Sem quakpuer

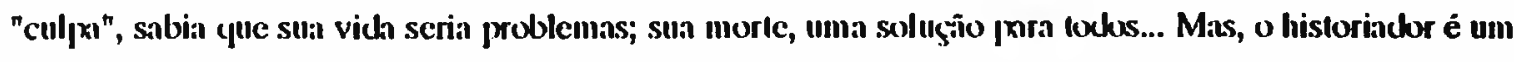
homem, um romano, e a histúria é um gênero lileririo.

Mau grado a lodas as leorias prenhes de arrazoados e revérberos cullurais sobre a renovaç̧ăo do comportamento humano, posta à parte a áreà do accidental, o homem repele e continuará repelinzlo o homem, sob pena de mudar de espécie. Alijacla da cargá contexlual da ficção lileríria de Terêncio, a lala com que Cremes, jocosamente lalvez, prelende justificar a Menedemo, na peça Heantontimorumenos, por que se mele em vida allheia, ć uma alirmação de sentido aberto, do teor dass prolecias, que carregam níveis de signilicaldos desconhediclos mesmo de quem as profere: Homo stum: Immani nihil a me alienmm puto. (Terêncio, Heantontimorumenos, 77). Um homem só pode fizer o que um homem pode fizer $\mathrm{c}$, sem dúvida, ludo o que polencialmente um homem pode lázer. Já nisso advertira 

n. 19, p. 9-28, (9)1.

bem o autor do Eclesiesstes: "O yue já loi, isso será. O yue já se lez, isso se lara; nada de novo debaixo do sol. - Nihil sub solem norim."

Como a juvenlude, cada geraçĩo, cada ćpoca literária, cada ćpoca cienlílica se deixa lacilmente levar pelo orgulho ilusionisla de estar vivendo no pináculo da história humaana, num muxklo de loclo novo. desvinculado de qualepuer pretérito, não diversamente do último andar de um arranha-céu que se vangloriasse de sua allura, conculcando, em lodos os senliclos, assim os fundamentos como os demais andares sobre que assenta. Não obslanle, seria em extremo fácil perceber quanto vai de miragem nessa vision, se louvesse empenho em considerar como pensaram e agiram os nossos ancesırais em períodos análogos do passialo humamo.

"História mero lestis temporum, Inx neritatis, nita memorine, magistra uitae, muntio uetnstatis..."
"A hislóriá , entim, leslemunha das épocas, luz. da verdade, vida da lembrançäı. mestra da vida, mensageira da anligüiidadc..."

(Cíccro, De Orratore. II, IX, 36)

Muila coisa, sem dúvida, se explica pelo alual, mas é bem mais ampla a herança que há misıer do passado como seu legílimo e mais profundo intérprelc.

A inslabilíssima situação da mulher. ao longo da história, vai da servidão mais abjela ao malriarcado mais leroz: do carimho mais malcrno ao mais virulento ódio: da mais encanladora inocêneia à mais viperina aslucia: da mais devola lealdade à mais requintada traição; uma siluação. diríamos. não diversa da do homem, mas, de cerlo. envolla $\mathrm{em}$ bem maior mislério que a dele. a menos para cke. que $0 \mathrm{kem}$ confessado cm lantas ocaisióes, algumas imorlalizadas pela arle, como no IV canlo da Eneidla:

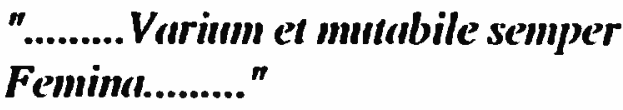

"Coisa sempre inslante c mulivel i a mulher

(Vergílio, Eneida, IV,569-70)

Em 1837, Victor Hugo acolhe em seu drama Le roi s'ammse (allo IV, c.2) dois versos quase proverbiais na França e que leriam sido, lendariamente, escritos por Francisco I, no século XVI: 
PETLRLINI, Ariovaldu A. Lucrécia e o ideal romano de mulher. Lingua e Lileralura, v. 16, n. 19 , p. $9-28,1991$.

"Souvent femme varie,

Bien fol esı qui s'y fie!"

Foi parafraseando o couplet de Francisco I, que Victor Hugo completou com mais dois versos:

\author{
"Une femme souvent \\ N'est qu'une plume au vent!"
}

que F.M. Piave compôs para o Rigoletto a célebre ária do Duque, que a música de Verdi eternizou:

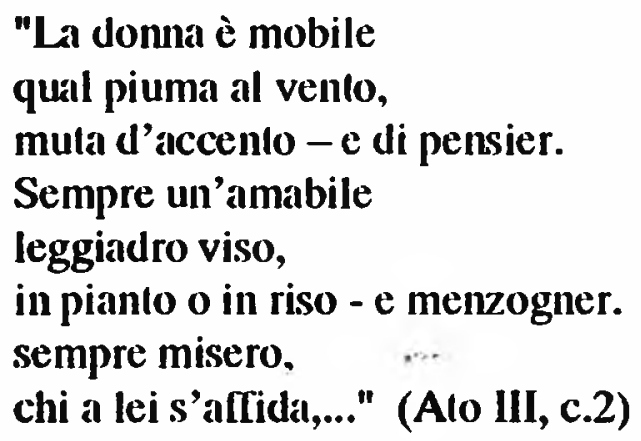

Até que ponto a nossa visão, atual, da mulher pela mulher e da mulher pelo homem é tributária do ideal romano anligo de mulher?

Não se trata de malbaralar o lempo, o estudo, o escrever num diletantismo alienado e tolo, mas cm contribuir, com diminula parcela que seja, a uma compreensão mais objelivá e jusla da parle feminina de nossa humanidade.

O texto latino que vai centralizar este modesto trabalho pertence a Tito Lívio (I, LVII-LVIII), um relato literário e histórico da violação e morte de Lucrécia, que a leitura dos séculos vem sagrando imorlal.

Releva considerar de antemão rat linha da hisloriografia perfilhada pelo autor, cujo lïlorromanismo, pessimisla com relação ao ontem e ao hoje, foge para o passado distante, em busca de normas e exemplos de comportamento em que possa espelhar-se a juventude contemporâneá. Buscam-se soluçóes para a crise do século I a.C., que Lívio, como outros historiadores, alribui unicamente a uma pretendida decadência de ordem élica, consoante a tradição catoniana. Essá a historiografia mimética, que se obriga a manter a representação icástica da vida humana, a tensão e a concentraçĩo dramática da representação Irágica, com evidentes objetivos paidêuticos, didascálicos, de recuperação moral das classes dominantes. Assim, não obstante a extraordinária cultura pessoal, toda a magia do poder descrilivo e narrativo de Lívio, há que lembrar seu idealismo romano, um perigo sempre iminente para a objetividade, uma vez que capaz de "informar" os mores e os exempla. 

n. 19, p. 9-28, 1901 .

Desta sorte, no relato da morle de Lucrécia, parece-nos que mais que o ideal romano primitivo de mulher, cumpre enlrever o ideal liviano, republicano, augustano de mulher, da monter familias, ć claro.

Anles de concetarmos o exante do lexlo sobre Lucrécia, convém iluminar o lema com alguns iextos paralcelos, subsídios para um melhor enlendimento do assunto.

É evidente que esse ideal romano de mulher pode reconsiruir-se, a parlir dos lextos, de duas manciras: ou diretamente, guando o lexto se prope a louvar um quadro positivo, ou ex opposito, quando o lexto relalta o negallivo.

Há uma passagem lambém de Tilo Lívio, onde se relere a dispula acirradíssina pela abrogançĩo da lei Ópia (195 a.C.) que, volacla durante a segunda guerra pünica por inicialliva do tribuno do povo C. Oppius. proibia as mulheres de possuírem mais de meia onça de ouro, de apresenlarem vestidos com diversas cores. de lazerem-se levar de carro em Romal ou em qualepuer oulra cidade, ou nos arredores delass num âmbilo de mil passsos, a menos que se trallasse dos sácrifícios públicos. Após violentos deballes, a lei loi abrogiala. mesmo porcue o trabalho político das mulheres, na lenlaliva de convencer os volanles, ló assistadtor. Mas o que nos interessa anjui e um trecho do discurso forlíssimo de M. Púrcio Cantão, encadeando razões contra al abrogaçūo da lei.

Si in sun quisque nostrum manre fammiline, Quirites, ins et matestatem uiri retinere instituisset, minus cum unversis feminis megotii haberemus: nume domi uich libertas nostra impotentia muliebri hic quoque in Foro obterinur et calcaunr: el, quia singulas sustinere non potmimus, universas horremus.

Qui hic mos est in publicum procurrendi, et obsidendi nias, et miros alienos appellamdi? Istud ipsum suos quaceque domi rogare nom potuistis? An blamdiores in pmblico quam in privato, el alicnis quanm uestris estis? quanquam ne domi quidem uos, si sni iuris finibus manronas comineret pudor, quare legis hic rogarentur abrogarenturue curare decuit. Maimes nostri mullam, ne privatam quidem, rem agere feminas sine anctore unhuerumt; in mamm esse parentum, fratrum, wirorum: nos (si diis placet) iam etiann rempublicam capessere eas patimur; et Foro prope, et concionibus, et comitiis immisceri. .......... Date frenos impotenti naturae et indomito animali, et sperate ipsas modum licenture facturas, nisi nos feceritis! Minimum hoc eorum est, qune iniquo animo feminne sibi ant moribus ant legibus iniuncta patiuntur: onnium rerum libertatem, imo licentiam (si uere alicere nolumms), desiderant. Quid enim, si hoc expngnamerint, non temnbum?

III. Recensete ommia muliebra inra, quibus licentiann earmm alliganerim mariores nostri, per quneque subiecerint miris: quibus ommiluws constrictas uix inmen continere potestis. Quid? Si carpere singula, et extorguere, et exatequari ad extremum niris patemini, tolerabiles uobis eas fore creditis? Extemplo, simml pares esse coeperint, superiores erumt. 

v. 16, n. 19, p. 9-28, 1991.

"Se cada um de nós, ó Romanos, livesse determinatlo manter sobre a suá mulher o direito e a autoriclade de marido. leríamos menos problemas (hoje) com lodas as mulheres. Agora que, no lar, a nossa liberdade loi vencida pela lailta de moderação de nossis mulheres, àui também no Forum é calleada aos pés e aniquilàla; por isso que não pudemos resistir a cadal uma em particular, nós a lememos a todas.

Que hábito é esse de correrdes em público, de siliardes as ruas e de vos dirigirdes a homens desconhecidos? Não pôde càda uma de vós pedir isso mesmo a scu marido, cm casal? Ou sois, acaso, mais persuasivas em puiblico do que $\mathrm{cm}$ particular, mais com estranhos do que com vossos maridos?

Contudo, se o pudor mantivesse as mães de lamília nos limiles de seu direito, nem sequer em casa realmente vos conviria cuiclar las leis que acyui se propōem ou se albrogam. Nossos ancestrais não permiliram que as mulheres traliassem de qualquer problema, mesmo doméstico, sem áulorização especial; (quiseram) que estivessem na dependência de seus pais, de seus irmãos e de seus mariclos. Nós, se assim apraz alos deuses, jí toleramos até que clas tomem parte nos negócios públicos, que freqüentem o Forum, que se misturem às discussões e aos comícios.

Dai rédeass à sua índolè imoderada. a seu capricho indomável, e esperai que por si próprias elas venham a dar à sua licençă o limile que vơs nāo ousástes pôr.

O que hoje solicitam ć a menor das desvantagens que as mulheres, com grande desprazer, suporlam que lhes tenham sido impostas jai pelos costumes, já pelas leis. Querem a liberdade de tudo, c mais (querem), para lalar a verdade, uma licença sem limites.

Se conquistarem isso, o que não lenlarão?

Linçai uma vista d'olhos sobre lodas as leis relerentes às mulheres, leis com que nossos antepassados mantiveram alada a excessiva liberdade delas, leis pelas quais esliveram sujeitas a scus maridos. $O$ que?! Se tolerardes que elas, de uma em uma, destruam essas leis, yue as expulsem, que se igualem de lodo aos homens, credes que vos será possível suporlá-las? Assim que começarem a ser iguais, de imediato nos dominarão."

A alutoridade, o domínio inconleste do pai, do marido sobre a mulher e as lillhass é o que Calt̃o, em época bem anlerior ao século 1 a. C., propõe como imprescíndivel no lar e, conseyüentemente, na vida social.

O trato da administração do lar e do Eslado é incumbência masculina. Maiores nostri mullam, ne privatam quidem, rem agere feminas sine anctore woluerunt; in manu esse parentum, fratrum, uirorum. E ironiza: Date frenos impotenti naturace et indomito animali, et sperate ipsas modum licentine facturas, nisi "los fecerítis!....... onmium rerum libertatem imo licentiam ... desiderant. Livres, seriam insuporláveis: Extemplo, simul pares esse coeperint, superiores erumt. 

n. 19, p. 9-28, 1991.

Cíccro, interpretando Platāo, ao expor os desmandos a que pode chegar a sede incontida de liberdade em época de anaryuia populista, enumera as várias consequîencias desastrosas daí advindas e entre elas a igualdade de direitos da esposa e do marido:

... ut necesse sit in eiusmodi republica plena libertatis esse omnia; ut et priuata domus omnis uncet dominatione, et hoc malum usque ad bestias perueniat... viri...

Ex quo fit, ut etiam serui se liberins geramt; wxores eodem iure sint quo

$$
\text { (Cícero, De Republica, I, 43) }
$$

"A ponto de ser necessário que, em tal lipo de Estado, luklo esbanje liberdade e que mesmo toda a família fique sem chefe, mal que se eslende alé os animais. A partir daí sucede que mesmo os escravos se dêem liberdades, que as esposas tenham os mesmos direitos que os maridos..."

Salústio, quando delineia magistralmente o perfil de Semprônia, expóe, de par com a viš̃o objeliva, algumas consideraçōes pessoais que traem a visão romana da mulher.

Em suma, sente-se no relrato dessa revolucionária a mulher que o romano esperava que sua mãe, sua esposa, sua fillha não lossem.

Sed in eis erat Sempronia, quae multa saepe uirilis audaciae facinora commiserat. Haec mulier genere atque forma, proteren uiro liberis satis fortunata fuit; litteris Graecis et Latinis docta, psallere, salutre elegantius quam necesse est probne, muka alia, quae instrumenta huwriae sumt.

Sed ei cariora semper omnia quam decus atque pudicitia finit; pecunine an fanne minus parceret hand facile discerneres; Iubicb sic accensn it snepius peteret uiras quann peteretur. Sed ea snepe antehac fidem prodiderat, creditum abiurmerat, cnedis conscia fueru, huzuria mgue imopia praeceps abierm. Vernum ingenium eius houd absurchun: posse wersis facere, iocum monere, sermone uti wel modesto,nel molli, nel procaci; prorssus muliae facetiae multusque lepos inerat.

$$
\text { (Salústio, Cat., XXV, 1-5) }
$$

"Entre elas estava Semprônia, que já cometera muitas vezes crimes de uma audácia viril. Essa mulher foi bastante afortunada pela ascenclência, pela beleza e ainda por seu marido e por seus filhos; instruída nas letras gregas e latinas, locava a cílara e dançava com mais arte do que convém a uma mulher honesla; e (era lambém ins(ruída) em muitas outras coisas que são instrumentos de devassidão. Tudo the era mais caro que sua honra e pudor. Não se conseguia saber se ela se 
PETERLINI, Ariovaldo A. Lucrécia e o ideal romano de mulher. Língua e Lileralura, v. 16, n. 19, p. 9-28, 1991.

imporlava menos com sua lortuna ou com sua reputação: trazia tão acesa a sensualidade, que mais freqüentemente abordava os homens do que era por eles abordada. Já antes traíra muilas vezes sua palavra, negara com juras uma dívida, fora cúmplice de malanças, degradara-se velozmente pela libertinagem e pela misériá. Mas não cra comum o seu talento: sabia compor seus versos, fazer rir, usar de uma linguagem ora modesla, ora le rna, ora desálorada; em uma palavra, havia nela muito espírito e muito encanto"

A mulher romana, faz-nos sentir Sálústio, era dignilïàla pela ascendência, pela beleza, pelo marido e pelos fïlhos. Com lal padrão não alina Semprônia: "tocava a cílara e dançava com mais arte do que conve'm a uma mulher honesta...; mais freqüentemente abordava os homens do que cra por eles abordada". O pudor feminino, os limites da dignidade, a concessão moderada à corte masculiná...são alguns predicados desejíveis numa mulher, mas que não encontravam em Semprônia um sujeito adequado.

Foi a essa mulher romana, mater familias, reservadíssima, responsável pelo lar, pelos tïlhos, pela dignidade da descenclência, comedida nas demonsIraçóes de carrinho e quase passiva no sexo, que os neóteroi trouxeram um mundo novo de liberdades.

"A revolução moral a que os poctas (novos) nos lïzeram assistir c para que eles mesmos contribuíram, consiste em ler feilo entrar o amor, o amor-paixão, o desejo e a satisfação nos relacionamentos que criam entre os seres laços morais, deveres e direilos.

Coube aos Romanos descobrir que existe uma ética do sentimento: a tradição ancestral outorgava o direito de cidadania à aleição lílial, áo respeito à esposa, aos deveres da palernidade e da malernidade, mas fingia ignorar o amor da carne que, lodavia, esla no centro de todo esse complexo. Era preciso ser um bom esposo e podia-se, por acréscimo, amar a própria mulher, mass isso não era imprenscíndivel nem mesmo muito conlessável.

Os poetas da época augustana... contribuíram fortemente... a liberar.... a mulher dessa prisão de respeito puramente formal onde retinham os costumes, para restituir-1he o direito de amar, de escolher, de consentir a sua fidelidade".2

Desnecessírio nos parece aduzir aqui os versos sem número de Catulo, a mais valiosa prova desse mundo novo que se oferecia à mulher romana: sobre o bene uelle das ternuras do coração, a mulher deve ter direito a amare da plenitude da carne, antes só permilido àss cortesãs e às amanles.

Huc est mens dedincta tua, mea Leshir, culpa, Alque ita se officio perdidit ipsin suo,

(2) GRIMAL, P'ierre. L'amour dì Rome'. P'aris, Sirciété d'Lidition "L.es Belles Leellres", 1979, p. 198. 

n. 19, p. 9-28, 1991.

Vt irmm nec bene uelle gutert tibi, si optumn fias; Nec desistere amare, onmial si facias.

(Calulo, 75)

"A tal ponto se rebaixou, por lua culpa, ó minha Lésbia, o meu espírito e de tal sorte se perdeu ele em seu devolamento. que jai não poderia cquerer-te bem, ainda que te tornasses a melhor das mulheres, nem poderia deixar de amar-le, ainda que para isso tudo lizesses".

Apesar dessa revolução nos limites do relacionamento homem-mulher, operada em boa parte pelos néóteroi e continuada. de certa torma, por Tibulo e Propércio, mas relomada principalmente por Ovídio às escêncaras, o munclo olĩcial Lazia por manter o respeilo ao pardrão ancestral da mulher respeitável. No diaa-dia vingara, porém, a liberação feminina do amor. máxime no âmbito das classes dominanles.

É assim que, a par com Ovídio, cujos versos triunfam o ammor livre c llhe valem o làvor da opiniẫo pública:

Militat ommis amans et habet sua castra Cupido;

Anice, crede mihi, militat ommis amans.

Sacpe maritorum somnis utuntur ammantes

Et swa sopitis hostibus arma monem.

C'ustodum transire mamus nigilumque caternas

Militis et miseri semper amantis opus.

(Ovídio, Amores, 1, 9, 1 e 25-28)

"Todo amante é un soldado c Cupido lem seu campo de batallaa;

Crcia-me, Álico, lodo amante é um soldado.

Com lireqüência se valem os amantes do sono dos maridos e, ençuanto dorme o inimigo, põem suas armass em ação.

Passar os cordóes de guardas e os corpos de sentinclas, esse é o trabalho do soldado e do pobre amante."

deparam-se-nos poemas de Horicio que, se cantou lambém o sensual do amorpaixão, não cantou menos o amor digno da mulher "de família":

Tutus bos etenim rura perambulat, mutrit rura C'eres almaque Faustitas, pacatum uolitamt per mare natuitac, 
PEIILELINI, Ariovaldo A. Lucrécia c o ideal romano de mulher. I dingua e Lileralura,

v. 16, n. 19, 1). 9-28, 1991 .

culpari meturit fides,

mullis polluitur casta domms stupris,

mos et lex maculosim edomuit nejas,

landantur simili prole puerperae,

culpam poena premil comes.

(Horicio, Odes, IV, V, 17-24)

(Quando estás presente, ó César Augusio,)

"O boi percorre seguro as paslageis.

Ceres e a Fecundidade criadora alimentam os campos,

voam os navegantes pelo mar pacilicardo;

a boa fé lem receio da suspeila,

a lámília honrada não é poluída por nenhum adultério;

o costume c a lei retrearam os desmandos impuros:

são louvadas as mães por causa do fillho parecido ao marido;

o castigo acompanha de perto o crime."

Auguslo. canla o poeta, é penhor de dignidade: sob sua égide, o adultério é banido; os desmandos contra a moral, embrida-os o cośtume a a lei; as esposas são lićis c os tillhos, legítimos; c há sempre um castigo para o crime.

Accita-se, no entanto, já alguma liberdade mesmo para a mater familias.

Horácio mesmo, num poema dedicado a Mecenas. não se furla a encarecer os dotes de suá esposá, indo além dos morais: a voz, os olhos, a dança, o espírito c ... a tidelidade:

Me dulcis dominae Musa Licymmiae cantus, me nohrit dicere lucidum fulgentis oculos et bene muturis

fidum pectus amoribus;

guam nec ferre pedem dedecuit choris

nec certare ioco nec dare brachia

ludentem niridis uirgimibus sacro

Dimne celebris die.

(Horício, Odes, II, XII, 13-20)

"Ordenou-me minha Musa que cu celebre

os doces cantos de Licínia, tua esposa,

os seus ollhos vivamente faiscantes

e o coração tiel a tĩo recíprocos amores; 

n. 19, p. 9-28, 1991.

que cu cante a cla, a quem nunca ficou mal dançar nos coros, nem em gracejos porliar, nem dar os braços, dançando, às formosas jovens, no dia movimentado da festa de Diana."

Que nem ludo cram rosas no reino de Auguslo. comprova-o de sobejo, v.g., a Lex Iulia de maritandis ordinibus (18 a.C.), o ius trium liberormm etc.. disposiçōes imperiais preocupadas com a manulençāo das famílias e a procriaçāo das classes dirigentes, base essencial da conlinuação do Império, no modo de pensar de Augusto.

É nesse sentido que Horácio ainda. ao referir-se às mulheres dos Cilas e dos Gelas, propōe-nas como modelo corretor dos costumes das romanas:

Campestres melius Scythae, quormm plaustra ungas rite iralume domos, uimunt et rigidi Getne

Illic matre carentibus

prinignis mulier temperat innocens

nec dotata regit uirum

coniunx nec nitido frilit adulhero;

dos est magna parentium

uirtus et metuens aherins uiri

certo foeckere castitas,

et peccare nefas aut pretium est mori.

(Horácio, Odes, III,XXIV, 9-24)

"Vivem melhor os Cilas das planícies, cujos carros puxam as casas errantes; vivem melhor os Gelas....

Ali uma mulher bondosa Irala bem os enleados carentes de

mãe; ali esposa alguma, valendo-se do dole, governa o marido, nem se fia em perfumado amante.

Precioso dole é a virtude dos pais e o caslo respeilo fundado $\mathrm{cm}$ segura aliança c lemeroso de oulro homem:

e (a idéia de que) cometer adultério é crime e morrer é seu preço."

Lá até as madrastas são bondosas, as esposas sāo submissas aos maridos e nōo os Irocam por perfumados amanles; lá são de exIrema imporlância a virtude dos pais, o respeilo ao casamento, a fidelidade recalada c a cerleza de que o adullério é crime púnivel de morle. 
PEIIERLINI, Ariovalch $A$. Lucrécin e o ideal romano de mullher. Linguta e Lileralura, v. 16, n. 19, p. 9-28, 1991.

Como um eco desses versos horacianos, vamos encontrar, bem mais tarde, um lexto de Tácito. que no elogio aos costumes dos germanos Iraça, ex opposito, um quadro do ideal romano da lámília e da mulher, ideal que ainda persistia entre os que sonhavam a restauração das passadas glórias de uma já antiga república: por isso os germanos são lorles, por isso loram fortes os antigos romanos. Um louvor aberlo, um dis larçado lamento; um hosana à morigeração carregada de esperanças de uma raça bárbara c nova, um requiem implícilo ao ocaso de um grande império...

Pancissima in tam mumerosa gente adulteria, quorum poena pracsens et maritis permissal: abscisis crinibus nudatum coram propinquis expellit domo maritus ac per onmem uicum uerbere agit; publicane enim pudicitiae mulla menin: non forma, non aetate, non opibus maritum inmenerit. Nemo enim illic uitia ridet, nec corrumpere et corrumpi sacenhmm nocatur. Atelins quidem adlunc ene cinitates in quibus tantum uirgines nubum et cum spe uotoque uxoris semel tronsigitur. Sic unum accipium marium guo modo ummm corpms unumque uitam, ne ulla cogitatio ultra, ne longior cupiditas, ne tamqunmm maritum sed iamounm marimonitum amem. Numerum liberorum finire ant guemqum ex algnais necare flagitium habetur; plusque ibi boni mores ualent quam alibi bonae leges.

Sun quemque mater uberibus alit, nec ancilis ac: muricibus delegantur. Sera innenum uenus, eogne incexhusta puberhas. Nec uirgines festinantur; endem iumentu, similis proceritas; pares ualidaceque miscentur; ac robora parentum liberi referum.

\section{(Tácito, Germanial, XIX c XX)}

"Em nação assim numerosa, são pouquíssimos os adultérios, cujo castigo é imediato c reservado alos maridos: corlados os calxelos, o marido a expulsa de casa nua, em frente dos parentes, e a corre a chicole por toda a aldeia. Nenhum perdão existe para a honra prostiluída; nem pela beleza, nem pela juventude, nem pelas riquezas encontrará marido.

Ali ninguém se diverte com os vícios, nem corromper e ser corrompido se chama moda. Melhor ainda, $\mathrm{em}$ verdade, naquelas cidades $\mathrm{em}$ que apenas as virgens se casaram e em que se vive umá só vez com a esperançá e o juramento de esposa.

Assim recebem um marido como um corpo e uma vida, de sorte que nenhum pensamento vá além nem vá mais longe o desejo, nem o amem como a um marido mas como o próprio malrimônio. Limilar o número dos lillhos ou malar algum dos agnados é lido por ignomínia e lêm mais valor aí os bons coslumes do que $\mathrm{em}$ outro lugatr as boass leis.

A cála um allimenta-o nos scios a própria mãe, nem são entregues os líIhos a escravas ou amas. 
PEETERLINI, Ariovaldo A. Lacrécia c o ideal romano de mulher. Lingun e Liferalura, v. 16, n. 19, p. 9-28, 1991 .

A sensualidade dos jovens é lardia e, por isso, a mocidade é vigorosa. $\mathrm{Nem}$ as virgens se apressam; a mesma juventude, igual estalura; iguatis e robustas se casam c os lilhos reflelem o vigor dos pais".

Com que sonha o escritor romano? Sonha com uma nova Roma, onde o adtillério, sobre ser raro, seja castigado de imediato - o da mulher, é claro; onde nem a belezal, nem a juvenlude, nem mesmo o dinheiro possa encontrar um novo marido para a honra prostituída; onde a depravaçã̃o não seja moda; onde as mulheres se casem virgens e uma só vez; onde se não limite o número dos fillhos, que as mães mesnass alimentarão a sejo e educarão pessoalmente; onde una juventude sadia, porque continenle, se calsari robusta, gerando para Roma fillhos vigorosos...

Não há mister de mais amplas elucidações; o lexlo é transparente e lala de per si.

Após essa visão panorâmica mas bastante ao nosso objetivo, visão que, evidentemente, poderia ampliar-se ad infinitum, tantos são os textos latinos antigos relativos ao lema, convém alduzir ainda alguns dados úleis ao bon entendimento da passagem liviana em pauta.

Silua-se o fato aqui relalado pelos lins do período dos reis romanos (509 a.C. aproximadanenle).

Um historiador moderno resumiria possivelmenle os sucessos políticos, referidos no texto de Lívio, nos seguintes termos: A aristocracia romana, havia mui10 lempo cm lïrme oposição aos reis, que vinham se apoiando na plebe, acabou por armar umá revoluçāo.

O rei Tarquínio encontra-se dislante de Roma, com o exćrcilo que o suslém. O paltriciado responde, lemporariamente, pelo governo da cidade de Roma, ou seja, um pátrício, Lucrécio, é o prefeito de Roma na ausência do rei. Júnio, o chefe da cavalaria, a primeira autoridade mililar depois do rei. também é um páIrício. São esses dois homens que armam a insurreição, coadjuvados pelos paitrícios Vallério e Tarquínio Colatino. Reúnem-se os conjurados em Colácia, na propriedade de um deles. Ali eles exibem ao povo o cadáver de uma mulher, a qual, dizem, se suicidara, para punir-se pelo crime de un til ho do rei. Tendo amotinado o povo de Colácia, dirigem-se, depois, a Roma c repelem a cena, sublevando a populaçẵo alé conseguirem depor e expulsar o rei.

Mas, na visão artística de Lívio, o dramálico, o trígico, a didascília, os exempla correm parclhas com a objetividade dos latos e os próprios acontecimenlos nasscem mais dos indivíduos, dos heróis e dos viles, e até das lendas do que dacpuito que a história atual selecionaria como verdadeiras e primeiras causas. Na Roma antiga, porém, a hisłória - cumpre nĩo esquecê-lo - é um gênero literário e é sobremodo difícil divisar em Tito Lívio onde licáam os limites entre o artista e o historiador, máxime quando sabemos que esse republicano de alma sonhava oferecer à ideologia do principiado o quadro majesloso da antiga grandeza pessoal c política dos ancestrais romanos, um estímulo torte de renascimento proposto a um presente marcalo pela frouxidão moral da classe dominante, onde mesmo os 
PETERLINI, Ariovaldu A. Lacrécia e o ideal romano de mulher. Lingua e Lilierntura, v. 16, n. 19, p. 9-28, 1.991 .

que propugnavam a morigeração não conseguiam esconder os desmandos que lhes ocorriam em casá, como sucedia com a própria lamília imperial de Augusto. Vamos agora a lo lexto.

Forte potantibus his apud Sex. Tarquinimm, ubi et Conlatimus cenabat Tarquinius, Egeri filius, incidit de uxoribus mentio. Summ quisque laudare miris modis; inde certamine accenso Conlatinus negat merbis opus esse; pancis id quidem horis posse sciri quantum ceteris praestet Lucretia sun. "Quin, si migor inurentae inest, conscendimus equos inmisimusque praesentes nostrarum ingenia? Id cuique spectatissimum sit quod in necopinato uiri aduentu occurrerit oculis."

Incaluerant uino; "Age sane" omnes; citatis equis umolam Romam. Quo cull' primis se intendentibus tenebris pertenissen, pergum inde Collatiam, ubi Lucretiam liaudquaquam "It regias murus; quas in conuinio huxuque cum aequalibus miderant tempus terentes, sed nocte sera deditam lamae inter lucubrantes ancillas in medio aedium sedentem inmeniumt.

Muliebris certaminis Iaus penes Lucretiam fuit. Adueniens uir Tarquiniique excepti benigne; uictor maritus comiter inmitat regios immenes. Ibi Sex. Tarquinium mala libido Lucretiae per nim stuprandae capit; cum forma tum spectata castitas incitat. Et tum quidem ab nocturno iumenali ludo in castra redeumt.

LVIII. Pancis interiectis diebus Sex. Tarquinius inscio Conlatino cum comite "no Collatian "lenit.

Vbi exceptus benigne ab ignaris consilii cum post cenam in hospitale cubiculum deductus esset, amore ardens, postquam satis tuta circa sopitique omnes uidebantur, stricto gladio ad dormientem Lucretiam uenit sinistraque manu mulieris pectore oppresso "Tace, Lucretia", "inquit; Sex. Tarquinius stum; ferrum in mamu est; moviere, si emiseris nocem." C'un panida ex somno mulier nullam opem, prope mortem imminentem uideret, $\| 1 m$ Tarquinius fateri amorem, orare, miscere precibus minas, uersare in omnes partes muliebrem animum. Vbi obstinatam widebat et ne mortis quidem metu inclinari, addit ad metum dedecus: cum mortua iugulatum sermum nudum positumum ait, "t in sordido adulterio necata dicatı!: Quo terrore cum uicisset obstinatam pudicitiam weht wictrix libido profecıusque inde Tarquinius ferox expugnato decore muliebri esset, Lucretia maesta tanto malo muntium Roman eundem ad patrem Ardeamque ad uirum mittit,' "It cum singulis fidelibus amicis "leniant; ita facto maturatoque opus esse; rem atrocen incidisse' Sp. Lucretius cum P. Valerio Volesi filio, Conlatimus cum L. Iunio Bruto uenit, cum quo forte Romam rediens ab mutio uxoris erat conuentus.Lucretiam sedentem maestam in cubiculo inmeniunt. Adurentu suorum lacrimae obortae, quaerentique uiro "Satin salue?" "Minime" inquit; "Quid enim salui est mulieri amissa pudicita? Vestigia uiri alieni, Conlatine, in lecto sum tuo; ceterum corpus est tantum wiolatum, animus insons; mors testis erit. Sed date derteras fidemque haud impune adultero fore. Sex. est Tarquinius qui hostis pro hospite priore nocte ui armatus mili sibique, si uos uiri estis, pestiferum hinc abstulit gaudium." Dant ordine omnes fidem; consolantur aegram animi auertendo no- 

n. 19, p. 9-28, 1991.

raun ab coacta in anctorem delicti : mentem peccare, mon corpus, et unde consilium afuerit culpam abesse.

"Vos, ingmil, mideritis quid illi debeanur : ego me etsi peccato absoluo, supplicio non libero; nec ulla deinde inupudica Lucretine exemplo uinet." Cultrum queen sub weste abditum habebat, eum in corde defigit, prolapsague in uolnus moribunda cecidit. Conclamut uir poterque.

\section{(T. Lívio, I,LVII-LVIII)}

"Estando estes a beber, ocasionalmente. em casa de Sexio Tarquínio, onde lambém ceava Tarquínio Colalino, filho de Egério, aconleceu de cair a conversá sobre suas esposas. Louvava cada um a sua de mil maneiras. Acesa a partir daí uma contenda, Colatino nega que haja necessidade de palavras: em poucas horas se poderá saber o quanto sua Lucrécia leve vantagem às demais. " Por que, já que estamos no vigor da juventucke, não montamos a cavalo c vamos pessoalmente ver as prenelas das nossas esposas? Que cada um creia apenas naquilo que the ocorrer diante dos olhos, à chegada inesperada do maridon. Tinham-se afogueado com o vinho. "Vamos pois!".(grilam) lodos. Incilados os cavalos, voam para Roma. Aí chegados quando as Irevas começavam a estender-se, continuam daí para Colácia, onde encontram a Lucrécia, nĩo como (linham encontrado) as noras do rei, que viram em suntuoso banquele, passando o lempo com as amigas, mass sentada no meio da casa entre vigilantes criadas, Irabalhando a lā por noile alla.

Coube a Lucrécia a vilória da aposta sobre as mulheres.

Foram acolhidos com afeição o esposo que chegava e os Tarquínios. O marido vencedor convida amistosamente os jovens príncipes. Foi então que o desejo perverso de esluprar Lucrécia à força lomou coria de Sexlo Tarquínio. Excilam-no assim a belcza como a reconhecida respeitabilidade. Por fim, após uma noile consigrada a divertimentos juvenis, retornam a acampamento.

Passados poucos dias, Sexto Taryuínio, sem que o soubesse Colalino, veio com um só companheiro a Colácia. Recebido aí cordialmente pelos que lhe desconheciam a intençāo. após o jantar, lendo sido conduzido ao yuarto de hóspedes, ardendo $\mathrm{cm}$ paixão, depois que ludo parecia bem seguro c yue lodos estavam adormecidos, desembainhâda a espada, veio âć Lucrécia, que dormia e, oprimindo o peilo da mulher com a mão esyuerda, disse: "Silêncio. Lucrécia; sou Sexio Tarquínio, lenho a espada na mão; morre rás. se deres .um pion".

Como, alordoada do sono, Lucrécia não visse, a um passo da morle, qualquer socorro, (começou) entāo Tarquínio a confessar-l he seu amor, a pedir, a mislurar ameaças alos rogos, a revirar para lodios os lados esse coraçióo de mulher.

Vemlo-a obstinada e que nem sequer pelo medo da morte se dobrava, juntou ao medo a desonra: disse que an lado dela morta haveria de pôr um escravo nu, degolado, para que se dissesse que fora morla em sórdido adullério.

Tendo, por esse lerror, a lascívia vergonhosal vencido a honra indomável e partido daí Tarquínio, orgulhoso com a conquista da honra de uma mulher. Lucrécia, acabrunhada de lamanha desgraça, envia o mesmo mensageiro ao pai, em 
Roma, e ao marido, em Árdea, para que venham cada um com um amigo de confiança; assim era necessário e urgenle; uma coisa terrível linha acontecido. Veio Espúrio Lucrécio com Públio Valério, filho de Volésio, e Colatino com, Lúcio Júnio Brulo, com quem se encontrara por acaso, ao voltar para Roma em razão do recado.

Encontraram Lucrécia senlada, pesarosa, no quarto.

À chegada dos seus, brotaram-lhe as lágrimas e ao marido que the pergunlava: "Está tudo bem?" - "De lorma nenhuma", respondeu, "que pode, em verdade, exislir de bom para uma mulher, se perde a honra? Há no teu leito, Colatino, veslígios de outro homem; mas apenas o corpo foi violado. meu coração eslá sem mácula. A morte será testemunha. Dai-vos as mãos direitas e lazei o juramento de que haverá uma punição para o adúltero. É Sexto Tarquínio que, inimigo, fazendo-se passar por hóspede, na noite passada, à mão armàda, tirou daqui um prazer funesto para mim c para ele, se é que vós sois homens".

Um a um, lodos dão sua palavra de honra; consolam a infeliz, desviando dela a culpa, coagida que lora, para o autor do crime: é a alma que peca, não o corpo, e de onde estiver ausente a intenção, estará ausente a culpa...

"Vós", disse cla, "cuidareis do que the é devido: eu. embora me absolva da culpa, não me desobrigo da pena; nem, depois de mim, nenhuma mulher desonrada viverá com o exemplo de Lucrécia."

O punhal que trazia escondido sob a veste, afundou-o no coração e, inclinada sobre a lerida, caiu moribunda.

Prorrompem em altos gritos o marido e o pai"

Para que não nos estranhe o lato de que homens romanos carregados de responsabilidades, praticamente fundadores da República, venham a desenfadarse, irresponsáveis, com uma aposta leviana c sobremodo perigosa, adverte-nos o historiador da juventude dos protagonislas - si uigor immentae inest -, levandonos ainda a somar a cla o potantibus e o incaluerant uino.

Chama a atenção do leitor, logo de início, a maneira como Lívio simula estilisticamente a rapidez da açĩo, numa mistura de estilo direlo e indireto, lão sem lempo para introduçóes, veloz como os cavalos e cavaleiros que voam para Roma: "Age sane" onmes; citatis equis amolant Romam. Os cavaleiros param em Roma, a fim de ver as noras do rei,ou seja, as esposas de alguns deles; mas o escritor não se detćm com eles, vai direto a Colácia, para encontrar Lucrécia, a ligura positiva da mulher romana, da esposa romana sentada no meio da casá, Irabalhando a lã com vigilantes criadas, mesmo por noile já avançada. Só então é que Lívio, à leição de um cineasla, projetarem contraste com o close dessa mulher exemplar, em segundo plano, as tiguras volúveis das outras esposas, a passar o tempo com as amigas em suntuoso banquele.

Homens romános, nem lhes ocorreu dispular da vitória de Lucrécia - sabiam lodos discenir a preceito no assunto. Muliebris certaminis laus penes Lucreliam fuit. 
PETERLINI, Ariovalch A. Luctécin c o ickeal romano de mulher. Língua e Lilleralura, v. 16, n. 19, p. 9-28, 1991.

A esposa afeluosa acolhe com carinho a marido e, hospilateira, aos jovens príncipes que o acompanham. E Sexto Tarquínio. um lïllo clo rei, habituado ă regalia do poder, deixa-se lomar do descjo, perverso sublinha Lívio, de violenlar Lucrécia à força. Por lerrível que pareçă, ainda ạui é o ideal romano de mulher que excita tal desejo, ou seja, nĩo apenas a belezal, mas " a reconhecida respeilabilidade" de Lucrécia.

É a mesma respeitosa e hospitaleira mulher quem recebe cordialmente o príncipe amigo do esposo e the faz. as honras da casa, sem saber a que vem.

Lívio cria, a seguir, um lerrível suspense: essa mulher modelo de honradez e virtudes femininas, que entre morlé c desonra oplaria de imedialo pela morle, vê-se lançada com violência nas garras de um alucinanle dilemia: morrer com sua honra, mas deixando aos seus a má lama de uma muller indigna, morla cm adullério com um escravo, ou ceder a honra, para poder relatar depois a verdade do estupro. O historiador se aproxima ayui do tealrólogo trágico e Iranslorma seu leitor num quase expectador. A plalcéia se anguslia, porcuanto ambas as saídas são por extremo agoniantes - em almbiss a porlat sce abre parla o solimento e o que deve ser feilo nĩo pode ser feilo.

O esposo e os filhos, pensaria uma romana, nĩo mereciam um nome de esposa c mãe desonrado. Uma coisa só cumpria liazer c Lucrécia a lez. Há que manter a honra do nome e da alma, ainda cue isso cusle, consoante o modo romano de pensar, a desonra do corpo, desonra irreversível....Tem de ceder e cede. A lascívia vergonhosa triunla da honra indomável.

A tragédia Iem sequüência, assim o planejou Lucrécia. Manda chamar o marido c o pai - rem atrocem incidisse. Não há verbo introdutor do estilo indire10, não hâ tempo para tanto, o desenlance é iminente.

Representante ideal do sistema a cue pertence, Luerécia sabe muilo bem o que sente o homem romano á respeito da siluação e enlende que as palavras de consolo - "é a alma que pecal, nếo o corpo" - são palavras, lalvez allé sinceras, mas que, se capazes de convencer a razão de um homem, jamais alcançariam serenar a alma de um romano e mesmo de uma mulher romana "que pode em verdade exislir de bom para uma mulher, se perde a honra?" De quem seria realmente essa indagaçāo? De Lucrécia? Da mulher romana? Do homem romano? De Lívio? Da ideologia do principado? Observe-se que a pergunla é retórica, i.é, constilui realmente uma asserção.

Lucrécia, após cobrar com juramento o casligo de Sexto Tarquínio e de calçar a promessa com um desalio femininamenle lerrível - "se é que vós sois homens" -, sem prestar ouvidos às fallas de conlorlo que sabe formais e inúleis, conclui : "eu, embora me absolva da culpa, não me desobrigo da penai; nem, depois de mim, nenhuma mulher desonrada viverá com o exemplo de Lucrécia."

E leal ralmente o "historiador" lecha a cena trágical e deixa ccoando, sublinhadas de sangue, as úllimas palavras de Lucrécia, uma mensaigem dura para loda a posteridade feminina de Roma: "O punlral que Irazia escondicto sob a veste, afundou-o no coraçāo e, inclinada sobre a ferida, cailu moribunda." 

v. 16, n. 19, p. $9-28,1991$.

Para que se possa avaliar melhor do inelutável desse desfecho, é imprescindível lembrar aqui um fator pouco científico mas de extrema importância, pois nele acreditavam os romanos antigos: uma mulher violentada ficava com o sangue impuro e isso era sem remédio. Lucrécia tinha consciência de que, se não morresse, sobre não ter como provar sua inocência - mors testis erit - traria para o marido e para a família sérios problemas. É o próprio Tito Lívio que, logo a seguir, põe na boca de um dos conjurados a seguinte fala de revolla e vingança:

Per hunc, inquit, castissimum ante regiam iniuriam sanguinem iuro, uosque di, testes facio me L. Tarquinium Superbum cum scelerata coniuge et omni liberorum stirpe ferro igni quacumque dehinc ui possim exsecuturum, nec alium quemquam regnare Romae passurum.

$$
\text { (T. Lívio, I, LIX, I) }
$$

"Por esle sangue castíssimo antes da ofensa do príncipe, disse, eu juro, e vos tomo por testemunhas, ó deuses, que hei de perseguir doravante, a ferro e fogo e com toda minha força, a Lúcio Tarquínio com sua criminosa esposa e toda descendência dos filhos, e que não hei de tolerar que nem eles nem outro qualquer "reine" em Roma.

Como pode ver-se no texto acima, a sangue era considerado "castíssimo ANTES DA OFENSA DO PRÍNCIPE", o que vale dizer que não o era mais, depois da ofensa, em que pese a inocência de Lucrécia.

Curiosamente, muitos séculos mais tarde, Shakespeare, em seu poema "The Rape of Lucrece", alude ao mesmo problema do sangue grosseiro, com uma parte negra, manchada pela ofensa. Vale, pelo curioso ler essa bela passagem, ainda que numa tradução portuguesa:

"Dizei como compor minha própria defesa!

Ou ao menos deixai que este refúgio encontre

De dizer que se o meu sangue grosseiro está

Manchado pela ofensa, a alma tenho sem mácula;

Violada não foi, nem nunca se inclinou

A complacências vis, mas sempre imaculada

Ainda se mantém na infecta prisão sua.

E esse sangue que ferve e do peito lhe sai

Dois lentos rios forma, a cercar duma rubra

Corrente o corpo seu, ilha que vem de ser

Saqueada e se estende, em toda direção,

Naquele horrendo mar, despovoada e nua. 

n. 19, p. 9-28, 1991.

De seu sangue uma parte está pura e vermelha. A outra é negra, a que foi por Tarquuínio manchada." ${ }^{3}$

Outro aspecto importante existe que merece lembrado. Lucrécia deveu escolher dolorosamente entre a honra e o suicídio e este não era caminho de felicidade no mundo dos mortos, como viver sem honra não era um caminho de felicidade no reino dos vivos...

É Vergílio quem nos lembra a tristeza dos que abandonaram por vontade própria a vida terrena:

Proxima deinde tenent maesti loca, qui sibi letum insontes peperere mami lucemque perosi proiecere animas. Quam uellent aethere in alto nunc et pauperiem et duros perferre labores! Fas obstat, tritisque palus (inamabilis undae alligat ....)

(Vergílio, Eneida, VI, 434-439)

"A seguir, ocupam os lugares vizinhos os tristes, que, inocentes, causaram a si a morte com a própria mão e, odiando a vida, enjeitaram suas almas. Quanto descjariam agora, no allo ar (da vida), suporlar a pobrezal e os árduos Irabalhos! Proíbe-o, lodavia, o destino e os aprisiona a sinistra lagoa de água delestável."

Lucrécia Irouxe problemas, em época bem posterior, a cristianismo de Santo Agostinho. Na sua Cidade de Deıs, leva o grande escritor algumas páginas na tentativa de explicar que o suicídio não era uma solução adequada. Acontece que a mentalidade já era cristā e Agostinho se defrontava com o sério problema das mulheres cristãs que, nas perseguições sofridas, linham sido violentadas pelos algozes, mas não linham sido morlas. Lucrécia, o grande exemplo da dignidade da mulher romana pagã, buscara no suicídio a remissão de seu nome. Que deveria fazer a mulher cristã violentada, para cuem o suicídio era um pecado grave e, portanto, a morle da alma? Agostinho não faz qualquer al usão ao problema romano do sangue tornado impuro, mas procura demonstrar que essas cristãs têm o direito à vida e ao respeito.

Os epitáfios foram feitos para fechar as vidas, mas alguns deles se constituem, em suas lembranças, verdadeiros programas de realização, ao descreverem

(3) SHAKESPEARE, W. "The Rape of Lucrece" in Obra Compleła. Traduçâo de Oscar Mendes. Rio de Janeiro, Editorn Nova Aguiar S.A., 1988, vol. III, p. 770-814.

(4) Augustin, S,. La Ciıé de Dieu. Paris, Libraire Garnier Frères, s.d., t.1, p. 33-39. (Liv. I, XVII - XIX). 
PEITRLINI, Ariovalub A. Lucrécia e o ideal romano de mulher. Liugua e Lileralura, v. 16, n. 19, p. 9-28, 1991.

os deveres cumpridos. Séculos e séculos alrás, muito anles de Lucrécia lalvez, talvez em sua época, sobre um lúmulo perdido à margem de velha esırada romana, alguém deixou gravado na pedra sepulcral da esposa, da mãe - quem sabe? - este pequeno epitáfio, resumo ideal da vida de uma esposa - mãe romana:

Hospes, quod dico paulum est: adsta ac perlege.

Hic est sepnilcrum haud pulchrum pulchrae feminae.

Nomine parentes nominaucrumt Claudiami.

Stum maritum corde dilexit suo.

Natos duos creatit: horum alterum

in terra linquit, alium sub terra locauit:

Domum seruauit, lanam fecil. Dixi. Abi.

(Epiláfio de matrona romana. O original eslá em forma arcaica)

Viajor, pouco ć o que lenho para dizer; pára e lê com alençẵo.

Este é o sepulcro não belo de uma bela mulher.

Por nome seus pais a chamaram Cláudia.

Amou de lodo o coração a seu marido.

Teve dois fillhos: destes a um deixou-o na lerra; ao oulro, pô-lo sob a lerra. Manteve a càsa, liou a lã. É o que cu tinha para dizer. Agora vai.

\section{BIBLIOGRAFIA}

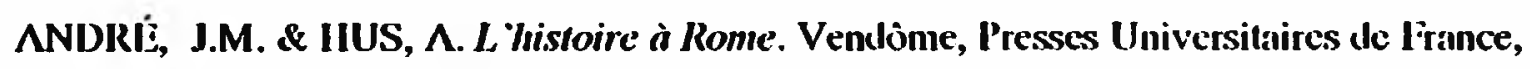
1974.

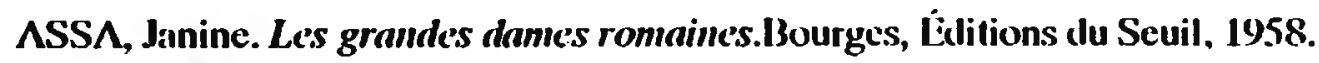

CA'IIN, Léon. En lisant Tîc-Live. Paris, Société d'Ĺklition "Les Belles L.ellres", 1944.

FヘU, Guy. L 'émancipation féminine dans la Rome' antiqute. P’aris, Sociélé d'Ĺlition "Les Belles Lettres", 1978.

FEDELI, P'solo. Le'ferautura Latina. Napoli, Lidizione "II Triponle", 1986.

GENTILI, B., PASOLI, E. \& SIMONETII, M. Storia della Litheratura Latina. 2. ed. Roma, Edilori Lilterza, 1977.

RliSUMÉ: L'idéal romain antique de lemme, qui peut être reconstitué au moyen des textes, soil direclement des tableaux favorables soit, ex opposito des visions negatives, est, sans duute, un des subsides dont peut se servir l’étude de la condition de la femme dans la pensée el dans la sociéłé de notre épxyue. A connailtre cet idéal nous aideront la crilique catunienne des revendications féminines en faveur de l'abrogation de la loi Opia; la mention de l'égalilé des droits de l'éponse e du mari come des mauvaises conséquences de l'anarchic populiste, dans le De Republica; les commentaires moralistes 
28 PETERLINI, Ariovalcto A. Lucrécia e o ickeal romano de mul her. Lingua e Lillerantura, v. I6, a. 19, p. 9-28, 1991.

de Salluste, dans le portrait de Sempronia; la révolution des poetae' noni, lorsyu'ils proposent l'exisrence d'une éthiyue du sentiment, accorctont a la femme le droil d'aimer, de choisir, de consentir a sa fidélité, la modération horatienne cntre l'amuur-passion et l'amour "digne" de la moter-familins; enfin, le texte immortet de la violation de Lucrèce, te Tïte-Live, oì nous entrevoyons les objectifs didascaliques de la récupération momle des classes dominantes el nous percevons la vision globale que le romain traditionnel avait de la fesnme, alors cnchainée pxur les préjugés yui violaient une morale rationnelle, au nom cle la "science" même de l'époụuc. 